4 Pickering JD, Henningsohn L, DeRuiter MC, de Jong PGM, Reinders MEJ. Twelve tips for developing and delivering a massive open online course in medical education. Med Teach 2017:39:691-6.

\section{Supporting the NHS using intense transformational change in a charitable specialist palliative care provider}

DOI: $10.7861 /$ fhj.Let-7-3-4

Editor - We share learning from our intense transformational change experienced during lockdown.

Following the 16 March 2020 announcement, we began urgent preparations to play our part to meet the needs of patients approaching the end of their lives with both COVID-19 and nonCOVID-19 terminal illness. Our aims were to protect the NHS and remain true to our charitable mission of caring compassionately for adults with terminal illness.

We responded with pace by redistributing the workforce within our three service areas (inpatient unit, living well and care at home; see supplementary material S2).

On our inpatient unit, we adapted our referral scoring system to favour admissions from hospitals to release acute beds, however our local integrated care system designated our ward as a 'cold site', due to the layout and its impact on infection control. By redeploying staff from other areas, we safely opened previously closed beds. Isolation rooms were created, with an adjacent personal proctective equipment gowning room.

We drastically reduced visiting hours for all but the imminently dying, so families were connected by daily calls from the multiprofessional team. We also used creative ways to connect patients and families, emotionally and spiritually, by shared objects including decorated pebbles, carved crosses and candles, as well as using video messaging.

The patient and carer group sessions, which our living well service would normally provide, were adapted to video calls. The data in Table 1 shows a dramatic change from traditional face-to-face contacts during the pre-COVID-19 era, to telephone support and video conferencing during lockdown.

The crisis required an expansion of our care at home service to support patients at home and in nursing homes. The advice and referral team increased its hours of operation from $8 \mathrm{am}-6 \mathrm{pm}$ to $8 \mathrm{am}-10 \mathrm{pm}$. The capacity for weekend specialist advice and care was enhanced with consultant weekend domiciliary visiting to support clinical decision making and end-of-life prescribing. Our

Table 1. Services at pre-COVID-19 (November 2019) compared with the first 2 months of the lockdown

\begin{tabular}{|c|c|c|c|}
\hline & $\begin{array}{l}\text { November } \\
2019\end{array}$ & $\begin{array}{l}\text { April } \\
2020\end{array}$ & $\begin{array}{l}\text { May } \\
2020\end{array}$ \\
\hline $\begin{array}{l}\text { Telephone calls to Phyllis } \\
\text { Tuckwell Hospice Care }\end{array}$ & 3,560 & 5,941 & 6,099 \\
\hline $\begin{array}{l}\text { Care at home face-to-face } \\
\text { contacts }\end{array}$ & 1,337 & 732 & 1,014 \\
\hline $\begin{array}{l}\text { Care at home non-face-to-face } \\
\text { contacts (including virtual) }\end{array}$ & 3,819 & 5,624 & 5,788 \\
\hline Living well face-to-face contacts & 575 & 3 & 6 \\
\hline $\begin{array}{l}\text { Living well non-face-to-face } \\
\text { contacts (including virtual) }\end{array}$ & 256 & 483 & 496 \\
\hline
\end{tabular}

hands-on nursing team (hospice care at home) launched a night visiting service. The care at home data for face-to-face dropped during the first month of lockdown, but bounced back in May, reflecting these additional service developments (Table 1).

The patient and family support team offered practical support through the care after death processes, emotional support via counsellor and a virtual funeral recorded by our chaplains.

The education team developed several free e-training modules on COVID-19, advance care planning and identification of frailty to support colleagues in discussing ceilings of care, do not attempt cardiopulmonary resuscitation and end-of-life care planning. These were taken up well by nursing homes.

Investments in leadership and team working, made over the preceding 2 years, paid dividends in being able to deliver change rapidly. With the government's $£ 200$ million support to hospices nationwide and using our reserves, together with generous contributions from our supporters, some of whom funded specific responses to COVID-19, we have been able to meet the additiona costs of service development. We were also indebted to our staff for their positive 'can do' attitude.

Learning and refining as we go has been a theme. The changes we made opened our eyes to new ways of working. Teleconferenced meetings and video calls to patients have been exceptionally well received. We have worked hard in the past to break down staff silos, and these melted away as staff found themselves working in new areas.

Having faced and overcome the issues at the peak of the pandemic, we are certainly not complacent as we consider preparations for a possible second wave this coming winter.

Cate Seton-Jones Medical director, Phyllis Tuckwell Hospice Care, Farnham, UK Nick Dando Consultant in palliative medicine, Phyllis Tuckwell Hospice Care, Farnham, UK

\section{Supplementary material}

Additional supplementary material may be found in the online version of this article at www.rcpjournals.org/fhj:

S2 - Redistribution of workforce due to COVID-19 pandemic showing the change to the delivery of services.

\section{Integrating sustainability in medical education}

DOI: $10.7861 /$ fhj.Let-7-3-5

Editor - We read with interest the article by Vanita Gandhi and colleagues which highlights the importance of integrating sustainability in medical education. ${ }^{1}$ We would like to bring to attention a student-led movement founded on the same principles and with incredible potential to trigger change.

Student MedAID is a student-led charity and society affiliated with the University of Edinburgh. We collect unwanted and out-ofdate medical resources from hospitals, organisations and members of the public throughout the UK. We then re-distribute them to under-resourced healthcare institutions abroad through medical students on electives, humanitarian health workers and other nongovernmental organisations.

To date, we have delivered equipment to 11 different countries, hoping to aid communities in need throughout the world. We have 
recently opened a new sister organisation in Leeds, and hope to open new branches in London, Aberdeen, Dundee and Oxford in the upcoming months. Our organisation has become integrated within local NHS trusts and universities throughout the UK, promoting cooperation at local, national and international level. We understand that what is urgently needed to reduce health disparities worldwide is increased legislation, healthcare funding and international collaboration. However, we hope to provide a short-term, student-led solution while advocating for long-term change.

By collecting surplus equipment, we aim to reduce the carbon footprint of the NHS and work towards a sustainable healthcare system both nationally and globally. We believe that every individual has the right to healthcare. In congruence with the true origins of the NHS and the ethos of Aneurin Bevan, which aimed to increase healthcare accessibility for all, we hope to advocate for the rights for those who may not have the voice to do so.

We have provided a unique platform for students to play a role in bridging the gap between waste in the NHS and shortage of medical equipment in resource-limited settings. Our members are committed to educating themselves and our audience on pressing topics in our society. Student MedAID hopes to be at the forefront of change, promoting Vanita Gandhi's message on sustainable education and aspiring to cultivate a community of compassion, respect and humility.

Nur Shazlin Shek Daud Medical student, University of Edinburgh Medical School, Edinburgh, UK

Alba Saenz de Villaverde Cortabarria Medical student, University of Edinburgh Medical School, Edinburgh, UK

\section{Reference}

1 Gandhi V, Al-Hadithy N, Göpfert A et al. Integrating sustainability into postgraduate medical education. FHJ 2020;7:102.

\section{Working from home in medicine during COVID-19 outbreak}

DOI: 10.7861/fhj.Let-7-3-6

Editor - In the article by Dr Hayes, it was noted that:

While the medical field has been slower than many professional areas to catch on to working from home, many trusts are already moving towards telephone or video outpatient appointments during COVID-19.'

Although working from home may be the best option during the COVID-19 crisis, it might be difficult for some medical staff to work from home, and reducing the workload at hospital and transferring to telemedicine might be good during a crisis but this is not be possible in all settings.

Telemedicine for appointed outpatient care is usually not possible in poor developing countries. Although medical staff or hospitals may have facilities for this, poor patients often have no IT facilities. Additionally, the promotion of the work at home concept, social distancing and decreased medical workload is used worldwide, some medical administrators with an unsafe attitude in developing countries might order their medical staff to work at risk without the use of new preventive technologies nor the working at home concept. ${ }^{2}$ Equipment might be necessary for working at home but good administration and management is also required.

Viroj Wiwanitkit

Honorary, visiting and adjunct professor, Dr DY Patil Vidyapeeth University, Pune, India, Hainan Medical University, Haikou, China and Joseph Ayo Babalola University, Ikeji-Arakeji, Nigeria

\section{References}

1 Hayes B. Working from home in medicine during coronavirus: What equipment do you need to get started and what can you do to help from home? FHJ 2020;7:163-4.

2 Saithong C. COVID-19 outbreak, primary health care center and vision of local administrator of primary health care center. Case Study Case Rep 2020;10:17-8. 